ALTERIDADES, 2020, 30 (59): Págs. 57-70 www.doi.org/ 10.24275 /uam/izt/dcsh / alteridades / 2020v30n59/Lopez

\title{
"No hay libertad política sin libertad sexual": a 50 años de Stonewall ${ }^{*}$
}

\author{
"No political freedom without sexual freedom": \\ 50 years from Stonewall
}

ERICKA LÓPEZ SÁNCHEZ**

TZINTLI JUÁREZ HERNÁNDEZ***

\begin{abstract}
The purpose of this work is to analyze theoretically how the sexual liberation movements of the sixties of the twentieth century deconstructed the social, political and cultural precepts of citizenship, public life, family and the idea of the body itself. Subsequently, after an ethnographic approach that allowed to register in the marches carried out in several local scenarios of the Mexican context 50 years after Stonewall, the main slogans that appeared on banners and blankets are registered to make an analysis with hermeneutical elements on them. Finally, we reflect on the elements of rupture with the old order from the struggles that are still being followed in favor of citizen models that recognize people's intimate life and diverse sexual orientations and gender self-identification.
\end{abstract}

Key words: normative citizenship, sexual citizenship, LGBT human rights, body, citizenship

\section{Resumen}

El propósito de este trabajo es analizar desde un punto de vista teórico cómo los movimientos de liberación sexual de los años sesenta del siglo xx deconstruyeron los preceptos sociales, políticos y culturales de la condición ciudadana, la vida pública, la familia y la idea del cuerpo mismo. Posteriormente, tras una aproximación etnográfica a las marchas realizadas en varios escenarios locales del contexto mexicano, a 50 años de Stonewall, se registran las principales consignas que aparecieron en pancartas y mantas para hacer un análisis con tintes hermenéuticos sobre las mismas. Por último, se reflexiona sobre los elementos de ruptura con el viejo orden a partir de las luchas que hasta hoy día se siguen a favor de modelos ciudadanos que reconozcan la vida íntima y las diversas orientaciones sexuales y autoidentificaciones de género de las personas.

Palabras clave: ciudadanía normativa, ciudadanía sexual, derechos humanos LGBT, cuerpo, ciudadanía

\section{El cuerpo y su potencia política}

$\mathrm{T}$ anto los ordenamientos de la fe como la razón han sujetado al cuerpo humano a su inexistencia, primero se priorizó el alma. El mito de Platón en su obra de Fedro sobre "la caída del alma en el cuerpo" es causa del pecado, el alma tiene necesidad del cuerpo y le es indispensable. Para Aristóteles lo importante es el alma,

* Artículo recibido el 26/07/19 y aceptado el 20/12/19.

** Universidad de Guanajuato, División de Derecho, Política y Gobierno, Departamento de Estudios Políticos y de Gobierno. Lascuráin de Retana núm. 5, zona centro, Guanajuato, Gto. <e_08renacimiento@hotmail.com>. orciD: https: //orcid. org/0000-0001-9929-5942.

*** Universidad de Guanajuato, División de Derecho, Política y Gobierno, Departamento de Estudios Políticos y de Gobierno. Lascuráin de Retana núm. 5, zona centro, Guanajuato, Gto. <tzint9@gmail.com>. 
al ser una sustancia que informa y vivifica a un determinado cuerpo. "El alma es al cuerpo lo que el acto de la visión al órgano visual” (Muñiz, 2010: 22).

En la época medieval, el cristianismo modificó las concepciones sobre el cuerpo, la inmortalidad del alma y el tratamiento del cuerpo como el depósito de los deseos carnales y objeto del pecado, y se hizo una escisión entre lo material y lo inmaterial. Los cristianos radicales optaron por la abstinencia como vía para lograr la purificación necesaria, ya que en el cuerpo se llevaba al demonio y se albergaban los deseos y apetitos incontrolados (Muñiz, 2010: 22-23).

Para Santo Tomás de Aquino el fin del cuerpo era el alma racional y las operaciones que derivaran de ella. En este entendido, el cuerpo puede llevar a Dios, pero sólo a través del intelecto, lo que implica una visión racionalista de la imagen corporal.

En la modernidad se privilegió la razón, al tiempo que se constituyó un cuerpo moderno cuyas características fueron la ruptura del sujeto con los otros, con el cosmos y consigo mismo; se instauró una estructura social de tipo individualista. "El sujeto en la modernidad posee un cuerpo. El cuerpo occidental es 'el lugar de la censura'." (Le Breton, 2002: 8).

En el trayecto de la episteme que va de los clásicos al mundo moderno, pasando por el medioevo, al cuerpo siempre se le ha concebido en una dualidad asimétrica: cuerpo y alma, cuerpo y espíritu, cuerpo y mente, o cuerpo y razón, dándole siempre un mayor peso a lo inmaterial y colocando a lo material como un mal necesario para albergar lo intangible. "La ciencia moderna ha reificado el cuerpo humano, lo ha colocado ahí: en su pura carnalidad, en su inmovilidad, en su permanencia, en su carácter de cosa concebible por la mente y la razón de un sujeto... ¿sin cuerpo?” (Muñiz, 2010: 20).

El cuerpo, materialidad constitutiva de los sujetos, invariablemente ha estado estigmatizado, ha resultado ser siempre la parte incómoda de la vida material de los seres humanos, de ser designado en la Edad Media como sede del pecado, en la modernidad, señala Dora García, "se introduce de manera violenta y de manera ordenada a los engranajes de la producción, y en donde se somete y controla para los intereses políticos" (2017: 31).

¿Por qué ese empecinamiento por neutralizar el cuerpo desde atributos negativos hasta sofisticadas técnicas políticas? El cuerpo es el territorio per se de los sujetos. “...yo no estoy delante de mi cuerpo, estoy en mi cuerpo, o mejor, soy mi cuerpo" (Merleau-Ponty, 1993: 167). El cuerpo es un lienzo de significados vivientes, captura una serie de inscripciones que muchas veces resultan amenazantes para el statu quo, porque revela la raza, el género, la clase social, la estética aceptada o negada, el funcionamiento anatómico y fisiológico saludable o enfermo, etcétera. El cuerpo es también una síntesis históricosocial que da cuenta de ordenamientos, disciplinamientos y diversas formas de control.

Las grandes conquistas a lo largo de la historia de la humanidad se han hecho a partir del sometimiento de los sujetos desde sus cuerpos. Para conquistar territorios geográficos es necesario conquistar primero territorios corporales. Según Foucault, los cuerpos tienen que ser arbitrados, y en ocasiones violentados, a fin de legitimar diferentes regímenes de dominación. "El cuerpo se presenta como el lugar primario para la operación de las modernas formas de poder, poder que no ha sido frontal y represivo, sino más bien, sutil, evasivo y productivo" (Muñiz, 2010: 30).

Las conquistas, los sometimientos, no se consiguen en un solo y gran acontecimiento, se logran con el control de la vida diaria, con las microprácticas, y la única manera de tener acceso a esas unidades ínfimas y constantes en el tiempo es a través de los cuerpos. El cuerpo es donde residen los procesos de disciplina y normalización. En el cuerpo se inscriben las leyes sociales, la moralidad y los valores (Muñiz, 2010: 30). "El cuerpo puede ser concebido como un lugar entre una física o interioridad vivida y una exterioridad sociopolítica que produce interioridad a través de la inscripción de la superficie exterior de los cuerpos" (Muñiz, 2010: 30).

Bajo este supuesto, el cuerpo es muy potente políticamente, y por ende debe ser sometido, desdibujado y neutralizado a partir de discursos religiosos, espirituales, políticos, económicos y sociales que propaguen la idea de que el cuerpo no importa, cuando importa tanto que hay que combatirlo.

El orden moderno trajo consigo el liberalismo, cuya expresión económico-técnica se plasmó en el capitalismo, y a la democracia como un modelo político para hacer sustentable el liberalismo. La democracia de apellido liberal se cimentó en un orden cívico-público de gran envergadura, que separó la vida pública de la privada y disciplinó a los cuerpos a partir de la entidad de ciudadanía.

Ante la necesidad de salvaguardar la propiedad privada y asegurar los frutos del trabajo, desde una concepción individualista, la democracia fungió como el mejor dispositivo político de control del poder y aseguramiento de los económicamente poderosos. El ámbito público fue designado como el espacio donde se dirime el bien común desde las lógicas de la razón. La razón es el principal instrumento para alcanzar la imparcialidad y lograr el verdadero bien común. 
Asimismo, se dispuso que los sujetos en su investidura de ciudadanos eran quienes podían estar en ese espacio público y, en consecuencia, la cualidad intrínseca al ciudadano fue y es la razón. "Si la razón conoce las reglas morales que se aplican universalmente a la acción y a la elección, entonces no habrá ninguna razón para que en la construcción de los juicios morales entren los propios sentimientos, intereses $o$ inclinaciones" (Young, 1998: 450).

La razón es la verdad para anular el cuerpo y sus adhesiones negativas como los sentimientos y las emociones del orden liberal democrático. En el paradigma de ciudadanía no hay lugar para la materialidad corpórea, es decir, para las identidades. La ciudadanía se convierte en un empaque que cubre a los sujetos con el manto de la razón y le quita sus especificidades corpóreas.

La razón en el orden cívico público es el ideal normativo y normalizador del cuerpo, ésta es la que hace posible el dominio y sujeción del cuerpo. La razón es la anatomía política que ejerce la dominación, es, por tanto, la cárcel del cuerpo, el instrumento de poder que lo forma y moldea. Es la mejor manera de sujetarlo sin que se perciba.

La ciudadanía se impuso como un modelo normativo, un modelo aspiracional del deber ser, y entre sus principales requisitos se estipuló la razón, que implica la dislocación de los sujetos de sus cuerpos, de sus emociones, sentimientos y pasiones, por ser considerados todos éstos la parte primitiva del ser humano, lo irracional.

La entidad ciudadana establece un sujeto estandarizado que no causa conflicto, pues se le abstrae de sus especificidades corpóreas, las que suelen ser diversas y generar tensiones. El espacio público se constituye así en un espacio racional homogéneo donde los acentos identitarios de ningún tipo tienen cabida, para así y sólo así alcanzar la imparcialidad que resulta ser el sello característico de la razón moral. Cabe señalar que "el compromiso con la imparcialidad da como resultado una oposición entre razón y deseo" (Young, 1998: 449).

La calidad ciudadana establecerá un estatus de igualdad, lo que hará posible la homogeneidad del espacio público; al neutralizar las particularidades corpóreas, los sujetos son arrancados de todas sus marcas identitarias con las que se posicionan frente al mundo e ingresan a la condición de igualdad sin ninguna autenticidad propia, sino a partir de la impuesta.
La condición ciudadana que propugna la igualdad tiene términos y condiciones muy claros y acordes al orden capitalista, patriarcal y democrático, que le permiten fabricar la igualdad. El ciudadano posee un cuerpo prototípico, y es el del joven varón, atlético, anglosajón, clase media, cisgénero y heterosexual. Quedando desdibujadas en condición marginal todas las corporalidades reales.

La idea de ciudadanía desde su origen privilegió aspectos predominantes del cuerpo de las sociedades europeas y norteamericanas. "Esta idea de ciudadanía produjo el reconocimiento corporal de unos cuantos y la exclusión sistemática de la mayoría a través de valores y normas depositadas en la ciudadanía occidental" (Enríquez y Martínez, 2016: 2).

El capitalismo democrático se rige por una normatividad que apela al clasismo, racismo, sexismo; que sólo reconoce lo heterosexual y se ampara en la cisnorma. ${ }^{1}$ Esta normatividad, como ya se discutió en párrafos anteriores, constriñe a los cuerpos para alcanzar un fin, el cual consiste en reproducir el orden capitalista que tiene como unidad mínima la familia patriarcal, monogámica y heterosexual.

Es por ello que al Estado moderno le interesa, y mucho, administrar la sexualidad. A través del marco legal, el Estado edifica parámetros en torno a una sexualidad normativa y determinista, que se sustentan sobre la base de una "verdad de sexo" fundamentada en términos binarios (masculino-femenino). Y esta verdad de sexos no da cabida a los tránsitos entre éstos o a la existencia de un sexo biológico "ambiguo" (Argüello, 2014: 142). Para Foucault el sexo es la intersección de la disciplina del cuerpo y el control de la población.

Las grandes expresiones de la modernidad: el capitalismo y la democracia, establecieron un orden social excluyente en lo económico, lo político y lo social, cimentado en el sometimiento de los cuerpos, de tal forma que éstos siempre están disponibles para las necesidades del poder mismo. El Estado moderno, en el ejercicio del uso legítimo de la violencia, posee toda la capacidad de aniquilar cuerpos ya sea física o simbólicamente.

\section{El boom de la diversidad: la enunciación explícita del cuerpo}

En los años sesenta se desplazó el debate político hacia los conflictos identitarios (reivindicaciones de género,

1 Un marco jurídico-legal que, para otorgar derechos, únicamente reconoce a los cuerpos que se mantienen en el tiempo con la identidad y género acordes al sexo asignado al momento de nacer. 
étnicas, culturales, preferencias sexuales, etcétera) (García Guitián, 2010: 398), haciendo a un lado los problemas de redistribución económica. Esto dio origen al surgimiento de los nuevos movimientos sociales, que se caracterizaron y se continúan caracterizando por la exigencia al reconocimiento y respeto de las diferencias y las identidades diversas que existen en el mundo (Melucci, 1999: 25-54).

La diversidad se constituyó como el aspecto central en la conformación de cada identidad colectiva, lo que representó la crisis de la homogeneidad ciudadana impuesta por la democracia liberal. Los nuevos movimientos sociales conllevaron, entre otras cosas, el reconocimiento de la diversidad material corpórea: mujeres, indígenas, personas de color, homosexuales, lesbianas. Todas colectividades marginadas de los beneficios legales, económicos, políticos y sociales.

La fabricación de la igualdad ciudadana tuvo su agotamiento en los años sesenta del siglo xx, implícitamente los sujetos se movilizaron para reapropiarse de sus cuerpos, sus historias, sus identidades y para ser reconocidos de manera digna desde las diversidades de cuerpos que habitaban. Y es que el mundo lo percibimos desde la posición de nuestros cuerpos en el tiempo y en el espacio y es condición misma de la existencia (García, 2017: 18).

De acuerdo con lo ya discutido, las especificidades corpóreas colocan a los sujetos en determinadas condiciones del mundo social. Los derechos, la vida digna está asignada para cuerpos que cumplen con determinadas condiciones estéticas, económicas, sexuales,

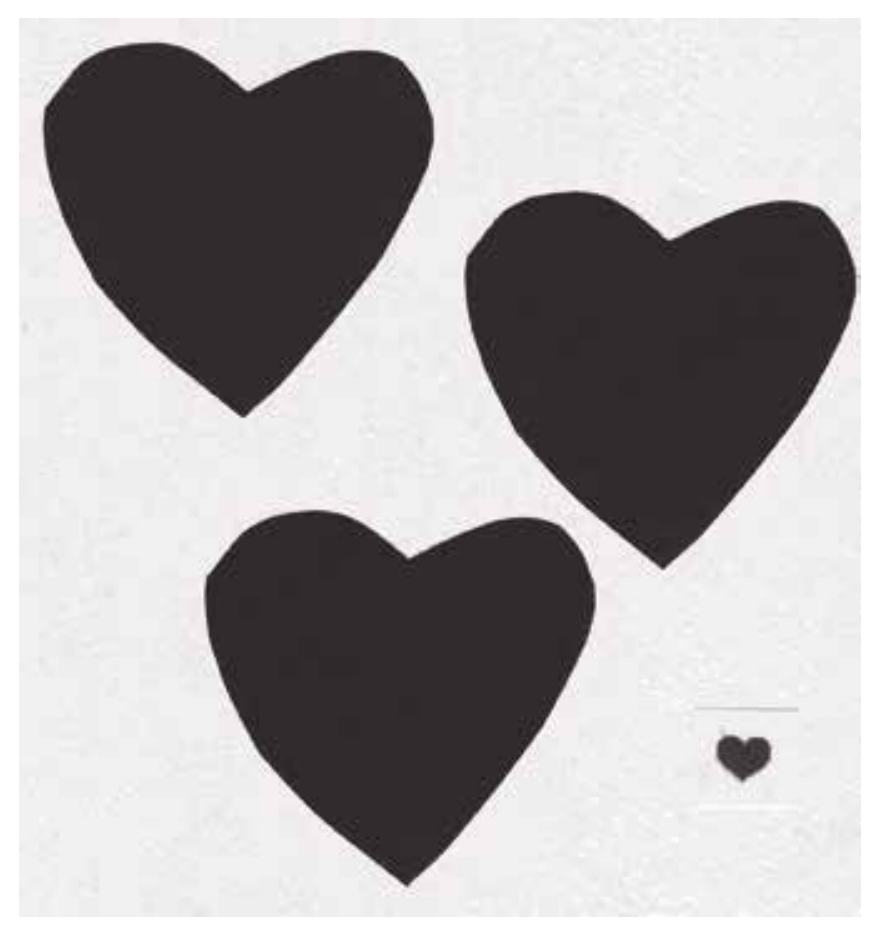

raciales, etcétera o hacen un trabajo cotidiano sobre el cuerpo para alcanzarlas.

Los nuevos movimientos sociales trastocaron otra de las máximas de la democracia liberal: el espacio privado. Este espacio se había mantenido, en apariencia, ajeno a las cuestiones políticas, en lo privado se podía hacer, decir y pensar lo que fuera, porque el Estado no se inmiscuía en la vida privada de las personas. Estos nuevos movimientos sociales llegaron a politizar la vida cotidiana y a dar respuesta a la colonización del mundo de la vida en tanto dinámica de extensión mercantilista a todos los aspectos de la vida.

En particular, los movimientos feministas llegaron a gritarle al Estado: "lo personal es político", a través de sus cuestionamientos a la separación del espacio público-privado, a la división sexual del trabajo, al control sexual de los cuerpos, al disfrute y gozo del erotismo, a las relaciones sexuales sólo para la reproducción, a las relaciones heterosexuales, al trabajo en el hogar, y a un sinfín de prácticas que someten el cuerpo femenino y todos aquellos cuerpos afines a éste.

Las feministas cincelaron la estructura conservadora de la sociedad de los años sesenta del siglo xx con la demanda de la liberación sexual, que consistió en abandonar los tacones, quemar el sostén, dejar el maquillaje, usar la píldora anticonceptiva para el goce y disfrute de la sexualidad y derrocar la idea del sexo vinculado única y exclusivamente con la procreación y dentro del matrimonio. Asimismo, se cuestiona la monogamia y se celebra la poligamia, la virginidad se desecha por mito, se da la bienvenida a personas homosexuales.

Las feministas pusieron el dedo en la llaga y desmantelaron la falsa no intromisión del Estado en el ámbito privado. Evidenciaron que el poder político invadía todas las esferas de la vida, todos los espacios tanto el público como el privado. Subrayaron que todo es político y que lo político comienza en el ámbito más íntimo del ser humano, como la relación sexual, el matrimonio, la familia (Trillo-Figueroa, 2016). Las mujeres

\footnotetext{
...encontraron su habitación propia, un espacio entre mujeres y para mujeres en el que pudiesen expresar libremente sus experiencias, hablar de lo callado hasta entonces [...] Los temas que se debatían eran las experiencias personales respecto a la sexualidad, la familia, la maternidad, o los sentimientos. Temas considerados personales y privados, por tanto, sin trascendencia política, que ahora eran analizados como causas de opresión de las mujeres y ponían de relieve que las relaciones personales son políticas, con ello ponían en práctica el lema de la época lo personal es político [Trillo-Figueroa, 2016].
} 
Todos los cuestionamientos y demandas de los diferentes grupos feministas de los años sesenta estaban fuertemente vinculados con las demandas de los grupos no heteronormados y no cisnormados, por tal razón, los movimientos feministas, como la misma teoría feminista, fueron las zonas de resguardo, diálogo y fortalecimiento de las movilizaciones LGBT (lésbico, gay, bisexuales y trans).

\section{Stonewall atenta contra el viejo orden}

En el barrio de Greenwich Village, de la ciudad de Nueva York, se ubicaba un bar llamado Stonewall Inn, famoso por recibir a personas homosexuales y trans en sus instalaciones; las festivas reuniones en su interior estaban rodeadas por un ambiente de clandestinidad, debido al contexto de opresión y persecución policial hacia la comunidad LGTB (Lesbianas, Gays, Travestis, Bisexuales) en la década de los [sesenta] en Estados Unidos.

Las redadas y la criminalización de las personas homosexuales por parte de la policía eran muy habituales, por lo que los administradores y los clientes estaban acostumbrados a los actos de violencia y el abuso de poder.

En una intervención común, las autoridades solicitaban las identificaciones de los asistentes y revisaban los genitales de las personas que usaban prendas consideradas femeninas para cerciorarse de su sexo; si se trataba de mujeres trans, eran detenidas.

La madrugada del 28 de junio de 1969, el Departamento de Policía de Nueva York realizó una redada en el Stonewall Inn. Sin embargo, cuando inició la operación, nada resultó como lo habían previsto.

Algunos clientes decidieron no mostrar sus identificaciones y las mujeres trans se resistieron a ser inspeccionadas. Otros asistentes se unieron a esta oposición y de un momento a otro la estrategia policiaca se transformó en una trifulca.

Un grupo de policías fue amurallado en el interior del lugar, mientras que en la puerta del bar se aglomeró un contingente de cerca de 150 personas, que estallaron luego que un agente agrediera brutalmente a una mujer lesbiana que había sido detenida y que solicitaba que sus esposas fueran desajustadas; algunos se abalanzaron contra el edificio para romper las ventanas del bar y otros intentaron volcar una patrulla.

Cuando terminó el enfrentamiento fueron detenidas 13 personas y varios civiles y agentes policiacos resultaron heridos. El hecho no pasó desapercibido, durante los días siguientes varios grupos de personas se manifestaron en contra de lo sucedido, acciones que también terminaron en conflictos con la policía.

Los hechos trascendieron en la creación de dos organizaciones que buscaban reconocer los derechos de las personas homosexuales, se fundaron el Gay Liberation Front y la Gay Activist Alliance, los cuales implementaron diferentes estrategias de visibilización, como marchas, manifestaciones y el abordaje a políticos durante eventos públicos (Balistrieri, 2019).

Las frecuentes redadas en el bar Stonewall y la forma como operaba la policía dan cuenta de la vigilancia sexual de los cuerpos, los cuales eran sometidos al uso legítimo de la violencia del Estado si estos cuerpos no cumplían con la cisnorma y si no eran cuerpos heteronormados.

La resistencia a esas redadas, que se conocen como los disturbios de Stonewall, marcaron la ruptura con la "normalidad" de esas prácticas violentas impuestas por el Estado, que ordenaban a los sujetos desde la intimidad, desde los territorios corporales que habitaban. Estos hechos de resistencia también marcaron un antes y un después en la visibilización y lucha por los derechos de las personas lesbianas, gays, bisexuales y trans.

Las manifestaciones que después se llevaron a cabo tuvieron que ver con la demanda de la liberación sexual: el cuerpo erotizado y las expresiones de género y la sexualidad diversa se colocaron en el centro de la disputa política. Los sujetos de la diversidad sexual y de género salieron a las calles reconociendo plenamente el cuerpo que habitaban; los repertorios de acción colectiva de estos grupos, así como el performance tuvo a partir de ese momento la exposición del cuerpo diverso y no disciplinado en la vía pública, por lo que la visibilización corporal fue el repertorio principal de acción de las movilizaciones inmediatas a los hechos de Stonewall y hasta el día de hoy permanecen vigentes.

Los movimientos de liberación sexual de Estados Unidos que se expandieron por todo el mundo cuestionaron de manera implícita la condición ciudadana de las personas LGBT, pusieron en evidencia que la ciudadanía estaba abstraída de su materialidad corpórea, y tanto su sexualidad como su expresión de género era controlada y administrada por el Estado, ${ }^{2}$ con lo cual lo personal era político, como en ese tiempo y contexto lo estaban señalando las feministas.

2 En Estados Unidos, en los años cincuenta y sesenta tanto homosexuales como lesbianas podía perder su trabajo y su familia, si se descubría que no eran heterosexuales o que eran personas trans. En concreto en Nueva York, todas las leyes estaban dirigidas contra la gente homosexual. La homosexualidad fue considerada en Estados Unidos una enfermedad mental hasta 
El orden conservador basado en una moralidad política represiva sustentado en el modelo parsoniano se vio trastocado cuando los sujetos emprendieron acciones colectivas y posicionaron sus luchas a partir de sus cuerpos. Para las personas LGBT su orientación sexual, su identidad y expresión de género pasó de la clandestinidad al orgullo, a la visibilidad.

En México, fue el 26 de julio de 1978 cuando por primera vez un grupo de personas (cuarenta entre homosexuales y lesbianas) se unió a una marcha en contra del régimen político, que demandaba la liberación de presos políticos. El contingente portó pancartas que exigían a su vez "liberación" de ciudadanos homosexuales por parte del sistema represivo dominante (Diez, 2011: 687). Esto representó el inicio de un movimiento social, posterior a la aparición de este pequeño contingente se formaron tres colectivos: uno de sólo hombres homosexuales, en el que a veces participaban algunas lesbianas, otro exclusivamente de mujeres lesbianas y otro más que aglutinaba a ambas identidades.

En 1979, homosexuales y lesbianas salieron de manera organizada a manifestarse en las calles bajo

...la encomienda de visibilizarse y enfrentar la violencia cotidiana y la discriminación de la que eran objeto en los ámbitos laborales, escolares, familiares y vecinales, así como en los pocos lugares existentes para socializar, ya que al ser éstos subrepticios no posibilitaban la defensa de sus derechos ni el combate de la represión policial [Fuentes, 2015: 32].

Estos grupos eran militantes de la izquierda y algunas/os de sus integrantes tenían formación feminista, así su lucha estaba en oposición al orden capitalista y patriarcal imperante de los años sesenta.

En Estados Unidos, los movimientos de la diversidad sexual y de género de los años sesenta y setenta tuvieron dentro de sus consignas: "Lesbian \& Gays Rights Are Human Rights", con lo que se empezaba a perfilar la aparición de la narrativa de los derechos humanos como una zona de potencial refugio para exigir derechos identitarios desde el lenguaje mismo de la democracia liberal, aquella que había implementado la condición ciudadana excluyente desde su propia naturaleza.

En México, las principales consignas que sintetizaron discursivamente la lucha de las personas LGBT fueron: "No hay libertad política sin libertad sexual",
"En mi cama mando yo", y retomaron la máxima de los movimientos feministas: "Lo personal es político". Estas consignas usadas en mantas, cartulinas y expresadas a gritos en las manifestaciones aludían al control del Estado sobre la vida privada de las personas, a la exigente obediencia hacia los términos y condiciones para alcanzar la calidad ciudadana, revelaban que el cuerpo y la sexualidad son cuestiones políticas.

Acostumbrado el viejo orden a ver denuncias de obreros y campesinos que apelaban al reparto justo de tierras, el aumento de salarios, a los derechos laborales -todas demandas del orden público-, fue sorprendido por los movimientos no heterenormados y no cisgénero, que aparecen colocando la sexualidad, la intimidad de su vida cotidiana y sus camas en el dominio público y en el espacio político, deconstruyendo así los pronunciamientos políticos basados siempre en ideas opositoras, pero nunca en cuerpos diversos y disruptivos, alejados del discurso natural biologicista.

\section{Los derechos humanos y su aporte a la construcción de ciudadanía LGBT}

El fin de la Guerra Fría posibilitó la aparición de un nuevo actor con presencia fuerte, cuya tarea sería contener la violencia que los Estados pudieran ejercer sobre sus gobernados o sobre otras naciones: los derechos humanos. A partir de 1948 estos derechos se constituyeron dentro de un orden supranacional al cual se encuentran adheridos los Estados democráticos. Los derechos humanos se instauraron de modo paulatino como un discurso de verdad que se colocó como libre de ideologías y surgió como un imperativo insoslayable de atender (Rabotnikof, 2005). "Hoy en día los Estados del mundo occidental asumen la obligación y el deber, en virtud del derecho internacional, de respetar, proteger y realizar los derechos humanos de sus sociedades" (López, 2019: 5).

Los derechos humanos son cada vez más el lenguaje básico de las reivindicaciones de las organizaciones de la sociedad civil; la zona de refugio de las personas LGBT fue primero la ideología de izquierda, como ahora lo es la narrativa de los derechos humanos. El instrumento más importante de los últimos tiempos creado por el liberalismo ha sido reapropiado por la mayoría

1973 y, en Nueva York, los tratamientos con descargas eléctricas no fueron abolidos de manera oficial hasta ese año. Las relaciones homosexuales, las muestras públicas de afecto y vestirse con ropa de sexo opuesto estaban prohibidas (EFEUSA, 2019). 
de los movimientos sociales centrados en lo identitario y se ha convertido en muchas ocasiones en la camisa de fuerza de los Estados democráticos capitalistas para reconocer a los grupos históricamente discriminados.

Todos los Estados-nación que se presumen democráticos tienen un compromiso con los derechos humanos mediante la ratificación de tratados internacionales; se comprometen a adoptar medidas y leyes internas compatibles con las obligaciones internacionales en esta materia, por lo que, en consecuencia, tienen el deber de prevenir las violencias de los derechos humanos, deben implementar todas las medidas y procedimientos necesarios con el fin de investigar sucesos violentos que laceren a las personas que gobiernan, sancionar a los responsables y reparar a las víctimas.

Las Conferencias de El Cairo (1994) y Beijing ( 1995) legitimaron, por primera vez, la construcción de la sexualidad como un derecho, al tiempo que promovieron la reflexión bajo argumentos científicos, con perspectiva de género y en el marco de los derechos humanos. Así, la Organización de las Naciones Unidas (ONU), en cuanto espacio prominente para la creación de normas y discursos internacionales, se ha constituido en un foro fundamental para debatir acerca de la sexualidad (Sánchez O., 2009: 105), pues, al ser el sexo la disciplina del cuerpo y el control de la población, estos temas forzosamente deben estar en dichos escenarios.

En 1997, en la Declaración Universal de los Derechos Sexuales del Congreso Mundial de Sexología, celebrado en Valencia, España, se reconocen los derechos sexuales como derechos humanos universales, basados en la libertad, dignidad e igualdad para todos los seres humanos Ocho años después de la Conferencia Mundial sobre la Mujer en Beijing, en abril del 2003, dentro de la Comisión de Derechos Humanos en Ginebra, Brasil, se propuso una resolución llamada Derechos Humanos y Orientación Sexual, tomando como modelo la Declaración Universal de los Derechos Humanos. Posteriormente, en 2004 y 2005 se introdujo también el tema de identidad sexo-genérica Fue así como el discurso de los derechos humanos se fue consolidando como uno de los espacios más prominentes para la creación de normas y discursos internacionales acerca de la dignidad, la libertad y la igualdad humanas de la población LGBTI [Serrato y López, 2018: 129].

Desde los años noventa del siglo pasado la narrativa de los derechos humanos ha sido el principal soporte argumentativo de denuncia de las personas LGBT para clamar por sus derechos, se ha consolidado con tanta fuerza que los derechos humanos han hecho posible instrumentar el litigio estratégico, el cual consiste en litigar mediante el uso de sistemas judiciales y mecanismos internacionales de protección con base $\mathrm{y}$ fundamento en los derechos humanos.

\section{Lo deconstruido, lo logrado y lo perdido en 50 años de lucha por el reconocimiento de la condición ciudadana LGBT}

A medio siglo de una lucha caracterizada por diferentes tonos y matices en Estados Unidos, América Latina y el resto del mundo se ha logrado deconstruir referentes en torno a la idea de ciudadanía que se sustentaban en la abstracción corpórea y que parecían de hierro: la constitución de los cuerpos sólo a partir del orden binario, la imposibilidad de transitar de una identidad de género a otra, el matrimonio heterosexual, lo monolítico de las familias heterosexuales, etcétera, todo lo cual ha trastocado fuertes entidades teóricas, entre ellas la ciudadanía liberal.

Estas deconstrucciones han tenido impactos diferentes en el mundo y muchas han permeado en modificaciones significativas al marco legal de los países, ya sea de manera nacional o sólo local. Pero también es cierto que en estas cinco décadas ha habido retrocesos y pérdidas de lo ganado.

Durante muchos años, Estados Unidos se consideró uno de los países más avanzados en cuanto a reconocimiento de derechos LGBT, no exactamente por tener aprobadas leyes de este tipo, sino porque, en ausencia de éstas, siempre respetó los derechos que corresponden a cada ciudadano sin importar su orientación sexual o identidad de género.

Hasta ahora, Estados Unidos reconoce en todo su territorio derechos como el matrimonio homosexual, cambio de identidad de género, derechos LGBT en materia de salud (durante la administración de Obama hubo una amplia cobertura de tratamientos de hormonización para personas trans), y se permitió tanto a hombres de la diversidad sexual como de género incorporarse al ejército. Y, en el ámbito escolar, los baños trans significaron uno de los avances más importantes aunado a la libre expresión.

Por su parte, México ha avanzado de manera importante en el reconocimiento de derechos de las personas LGBT, pero sólo a nivel local, concretamente la Ciudad de México es la entidad federativa que más ha avanzado desde el 2007. Empero, en el contexto latinoamericano, Brasil, Argentina y Uruguay llevan la delantera en esta materia. A continuación se presenta un cuadro que describe los derechos LGBT admitidos en América Latina. 
Tabla de reconocimiento de derechos lgBt en América Latina

\begin{tabular}{|c|c|c|}
\hline País & Núm. de derechos & Derecho (s) \\
\hline Argentina & 10 & $\begin{array}{l}\text { - Adopción } \\
\text { - Matrimonio igualitario } \\
\text { - Heredar a la pareja (por fallecimiento) } \\
\text { - Identidad de género } \\
\text { - Ejercicio del voto (para personas trans) } \\
\text { - Seguridad social (salud) } \\
\text { - Educación } \\
\text { - Familia (reproducción asistida) } \\
\text { - Intimidad } \\
\text { - Pensión a la pareja }\end{array}$ \\
\hline Bolivia & 2 & $\begin{array}{l}\text { - Identidad de género } \\
\text { - Unión civil }\end{array}$ \\
\hline Brasil & 11 & $\begin{array}{l}\text { - Trabajo } \\
\text { - Identidad de género } \\
\text { - Adopción } \\
\text { - Unión estable } \\
\text { - Pensión a la pareja } \\
\text { - Heredar a la pareja (por fallecimiento) } \\
\text { - Seguridad social (salud) } \\
\text { - Seguridad social (enfermedades, discapacidad, maternidad, desempleo, pensiones y muerte) } \\
\text { - Familia (reproducción asistida) } \\
\text { - Matrimonio igualitario } \\
\text { - Uso de nombre social para los contribuyentes }\end{array}$ \\
\hline Chile & 3 & $\begin{array}{l}\text { - Unión civil } \\
\text { - Heredar a la pareja (por fallecimiento) } \\
\text { - Identidad de género }\end{array}$ \\
\hline Colombia & 6 & $\begin{array}{l}\text { - Heredar a la pareja (por fallecimiento) } \\
\text { - Seguridad social (salud) } \\
\text { - Pensión a la pareja } \\
\text { - Adopción } \\
\text { - Identidad de género } \\
\text { - Matrimonio igualitario }\end{array}$ \\
\hline Costa Rica & 4 & $\begin{array}{l}\text { - Seguridad social (salud, prestaciones sociales) } \\
\text { - Derecho a la no discriminación laboral } \\
\text { - Pensión a la pareja } \\
\text { - Seguridad social (salud) }\end{array}$ \\
\hline Cuba & 2 & $\begin{array}{l}\text { - Seguridad social (salud: cirugía de reasignación de sexo) } \\
\text { - Trabajo }\end{array}$ \\
\hline Ecuador & 6 & $\begin{array}{l}\text { - Trabajo } \\
\text { - Unión civil } \\
\text { - Ejercicio del voto (para personas trans) } \\
\text { - Identidad de género } \\
\text { - Seguridad social (salud) } \\
\text { - Matrimonio igualitario }\end{array}$ \\
\hline El Salvador & 1 & - Derecho a la no discriminación laboral \\
\hline México & 3 & $\begin{array}{l}\text { - Ejercicio del voto (para personas trans) } \\
\text { - Seguridad social (guarderías, salud, herencia, apoyo en caso de orfandad) } \\
\text { - Pensión a la pareja }\end{array}$ \\
\hline Panamá & 2 & $\begin{array}{l}\text { - Identidad de género } \\
\text { - Derecho a la vida (despenalización de la homosexualidad) }\end{array}$ \\
\hline Perú & 1 & - Identidad de género \\
\hline Uruguay & 10 & $\begin{array}{l}\text { - Libertad de expresión } \\
\text { - Unión civil } \\
\text { - Adopción } \\
\text { - Identidad de género } \\
\text { - Familia (reproducción asistida) } \\
\text { - Matrimonio igualitario } \\
\text { - Educación } \\
\text { - Derecho a la vida (una vida plena) } \\
\text { - Seguridad social (salud) } \\
\text { - Trabajo }\end{array}$ \\
\hline
\end{tabular}

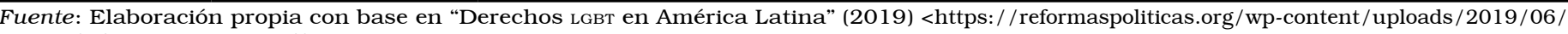
Diversidades-v_17_jun_19.pdf>. 
El hecho de que 13 países de América Latina reconozcan al menos un derecho (como El Salvador y Perú) e incluso amparen hasta 11 derechos (en el caso de Brasil) da cuenta de la deconstrucción que ha sufrido la visión hegemónica de lo heteronormado y cisgénero de los derechos políticos, civiles y sociales que otorgan la condición ciudadana. Asimismo, revela cómo se han tenido que flexibilizar las estructuras de poder en torno a las nuevas demandas que se resguardan en los derechos humanos.

Estados Unidos y Brasil enfrentan una situación más compleja que otras naciones del continente americano que reconocen derechos; la llegada de presidentes como Donald Trump en Estados Unidos y Jair Bolsonaro en Brasil ha sido preocupante, ya que éstos han manifestado su postura negativa hacia la población LGBT y, por tanto, su no apoyo e incluso persecución.

Durante la administración de Trump se han dejado sin efecto la norma que permitía a los estudiantes trans usar el baño o vestidor de su elección, las nuevas protecciones de atención de salud para las personas trans, así como la negación de su incorporación al ejército del país y a los derechos que se habían ganado durante la administración de Barak Obama.

En Brasil, el número de crímenes de odio va en aumento. La creciente ola de violencia hacia esta población es una respuesta a la aprobación del matrimonio igualitario. Pero también se está asesinando a las personas trans, específicamente mujeres.

Lo que sucede en Brasil es una constante en varios países del continente americano y del mundo; en la medida en que se reconocen derechos, los crímenes de odio no cesan, incluso a veces aumentan, y las principales víctimas son las mujeres trans y los hombres homosexuales. Todavía hoy 72 países del mundo consideran un crimen el ser homosexual, mientras sólo nueve países contemplan la no discriminación por razones de orientación sexual en sus constituciones Pese a que la homosexualidad y la condición trans salieron del catálogo de enfermedades, únicamente en tres países están prohibidas las terapias de reconversión (Brasil, Ecuador y Malta) (Museo Memoria y Tolerancia, 2018).

En medio de estos avances, estancamientos y retrocesos se ha desarrollado una dinámica muy particular de lo deconstruido en dos vertientes: lo sociosexuado y lo escandalosamente disruptivo. Las deconstrucciones sobre el cuerpo, la sexualidad y sus implicaciones en el ámbito político han alterado la democracia liberal, el modelo de ciudadanía normativa, la idea del cuerpo biológico-natural, la idea heterosexual de la familia, el amor-erótico heterosexual, lo cisnormado y demás aspectos socioculturales que otorgan certeza al mundo liberal-capitalista-democrático.

Por un lado, hay deconstrucciones como el matrimonio igualitario, las familias homoparentales, la adopción entre parejas del mismo sexo, que si bien apelan a una democracia sexual, entendida en términos de políticas de equidad de género y reconocimiento de la diversidad sexual y de género, no es del todo ajena a la rearticulación de cierta jerarquía sociosexuada, "en la que junto al heterocentrismo imperante, se generan nuevas homonormatividades en las que la familia y la pareja como modelos hegemónicos de organización social siguen siendo centrales" (Sabsay, 2011: 32).

Además, están las deconstrucciones más disruptivas como la identidad trans, drag queen, el cuestionamiento y la ruptura con la identidad monolítica inamovible de género en total correspondencia con el sexo asignado al momento de nacer, los cuerpos no binarios, queers, que trascienden el ser clasificados única y absolutamente a partir de dos esquemas: hombre o mujer, las personas que se identifican con el género fluido y una variante de autoidentificaciones y usos del cuerpo que conllevan cambios bruscos y liberadores, que obligan la modificación de marcos legales de las prácticas democráticas más tradicionales, como el ejercicio del voto (en México existe un protocolo para que puedan sufragar las personas trans). Al mismo tiempo que estas deconstrucciones obligan a que la medicina, la economía, la antropología, la sociología y todas las ciencias humanas, sociales y naturales se repiensen desde sus premisas teórico-conceptuales.

Hablando de lo disruptivo en la ciencia médica, ahora es cada vez más común escuchar sobre las cirugías de reasignación de sexo y sobre la endocrinología al servicio de las personas trans para medicar y vigilar su hormonización, lo que está cambiando la política pública en torno a la salud.

Y el arte no ha quedado exento de estas deconstrucciones, la lucha por la existencia de cuerpos diversos (trans, lesbianas, homosexuales) que no necesariamente corresponden con la estética occidental del mercado, así como los feminismos y las miradas subversivas, han hecho posible el cine posporno, que rompe con el erotismo hegemónico del patriarcado y del capitalismo, que propone otras formas de erotizar el cuerpo (desde la diversidad de los cuerpos), distintas de las impuestas por el dispositivo de la biopolítica.

El arte-voguero de las drags queens modificó el arte-performance (ya de por sí alternativo, marginal y subversivo). Asimismo, el ballroom se ha constituido una expresión artística irreverente de la normatividad, disciplinamiento y estética de los cuerpos, donde se deconstruye, entre muchas cosas, lo binario de los 
sexos a partir del vestuario y los movimientos armónicos y escandalosos basados en pasarelas de moda del mundo occidental (Vogue). Estas expresiones artísticas están tomando gran relevancia como forma de resistencia y subversión (véase foto 1 ).

Las deconstrucciones han sido lentas, pero diversas, unas más profundas que otras, desiguales en el mundo y dentro de cada experiencia nacional, lo que más se ha trastocado es la estructura político-jurídica de los países que han aceptado el reconocimiento de derechos, pero la estructura sociocultural aún se resiste, se opone y muchas veces reacciona con violencia, de ahí la existencia de zonas (que no países) friendly LGBT.

\section{A 50 años de Stonewall y las marchas del orgullo en el contexto mexicano}

La Marcha del Orgullo que se celebra en México desde hace 41 años -y que tiene como uno de sus antecedentes los acontecimientos de Stonewall en 1969- ha tomado tintes muy particulares al paso del tiempo, poco a poco ha dejado de ser centralista, de llevarse a cabo únicamente en la Ciudad de México, para dar paso a su realización en escenarios locales, en entornos muy pequeños, antes impensables. Así, el contexto local ha cobrado relevancia en la celebración de las marchas del orgullo gay; en algunas localidades, estas manifestaciones vinculadas a conmemorar los hechos de Stonewall o la aparición de la primera marcha de la diversidad sexual y de género en México, se efectúan desde hace 15 años o más. Por ejemplo, este 2019 Aguascalientes cumplió 18 años de realizar estas manifestaciones, Cancún 16 años, Playa del Carmen 15, Chihuahua 12, Chilpancingo 18, Ciudad Juárez 15, Tijuana 14, sólo por mencionar algunas ciudades.

Cada sitio se ha reapropiado de las marchas y esto se puede observar en la manera en que las organizan y la forma como las nombran, por ejemplo: Marcha de las Diversidades Afectivo Sexuales; Marcha Estatal del Orgullo LGBTiQ, Marcha del Orgullo, Marcha del Orgullo LGBtтt, Marcha del Orgullo LGBtтti,, Pride

Foto 1

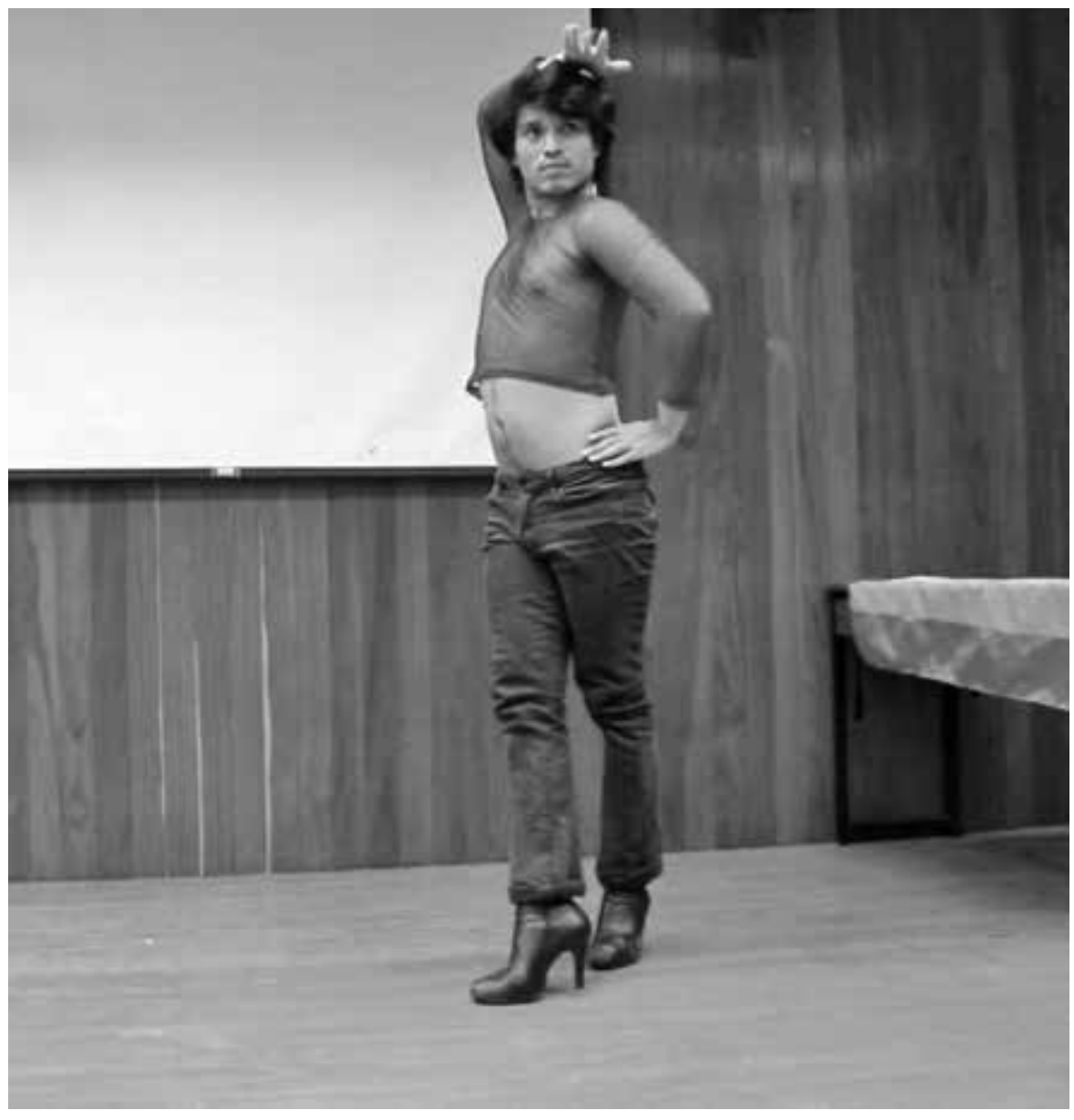

Foto: Tzintli Juárez. 
Aguascalientes, Pride León, Marcha de la Diversidad Sexual, Marcha en contra de la Homo, Lesbo y Transfobia, etcétera.

Cada forma de nombrar a las marchas da cuenta de cómo se entiende en cada localidad la diversidad sexual y de género, así como sus demandas, necesidades y organizaciones de lucha y resistencia. El nombre mismo permite saber si las personas organizadoras y la localidad misma poseen un conocimiento sobre la diferencia entre la orientación sexual y la identidad de género, cómo entienden lo trans, qué identidad predomina y quién tiene el liderazgo, si es una marcha elegebetera o con una clara diferenciación de cada una de las identidades y reconocimiento de demandas específicas, así como el lugar que ocupa cada una de las identidades, entre otras cosas.

El modo como se desarrollan también es diverso, lo que permite comprender que la lucha por la visibilidad y el reconocimiento de derechos a favor de las personas de la diversidad sexual y de género no es homogénea, lo que ocurre en la Ciudad de México dista mucho de lo que sucede en los escenarios locales y esto va aparejado al reconocimiento de derechos LGBT en México. Existen ciudades friendly, mas no lo es el país entero. Asimismo, las entidades federativas que han reconocido derechos a favor de las personas de la diversidad sexual y de género han reconocido diferentes derechos que impactan positivamente en algunas de las identidades, pero dejan fuera otras.

Como ya se ha mencionado, en un contexto donde impera el discurso de verdad de los derechos humanos, es casi imposible que éste no permee en las demandas de las personas manifestantes. Un fenómeno muy peculiar de las marchas del 2019 celebradas en diferentes ciudades fue el discurso explícito o implícito de los derechos humanos y los valores tradicionales.

Las consignas visibilizan en gran medida la potencia que hoy día tienen los derechos humanos. Las consignas de 2019, además de sustentarse en estos derechos, se han fusionado con los valores tradicionales y con la identidad de la diversidad para dar lugar a una reapropiación desde la legitimidad de los discursos vigentes. Veámoslas.

“Amar es un Derecho humano". Fue habitual leer esta frase en pancartas de diferentes marchas que conmemoraban el orgullo. Nadie puede oponerse al concepto del amor, porque está vinculado con un sentimiento virtuoso que permite la tranquilidad, alcanzar la felicidad y eliminar cualquier sentimiento y acto violento que atente contra los seres humanos.

En sí mismo el verbo amar es una acción potente que cobra vital importancia en un contexto violento, inseguro y amenazante como el que vivimos. Pero, anclado como un derecho humano, adquiere un sentido de verdad indiscutible, que tiene como fin desarticular cualquier oposición conservadora.

Nadie puede oponerse a la acción de amar y mucho menos contradecir los derechos humanos, pues esto lo colocaría en el terreno de lo intransigente, lo retrógrada y, en consecuencia, en lo antidemocrático y violento (véase foto 2 ).

Foto 2

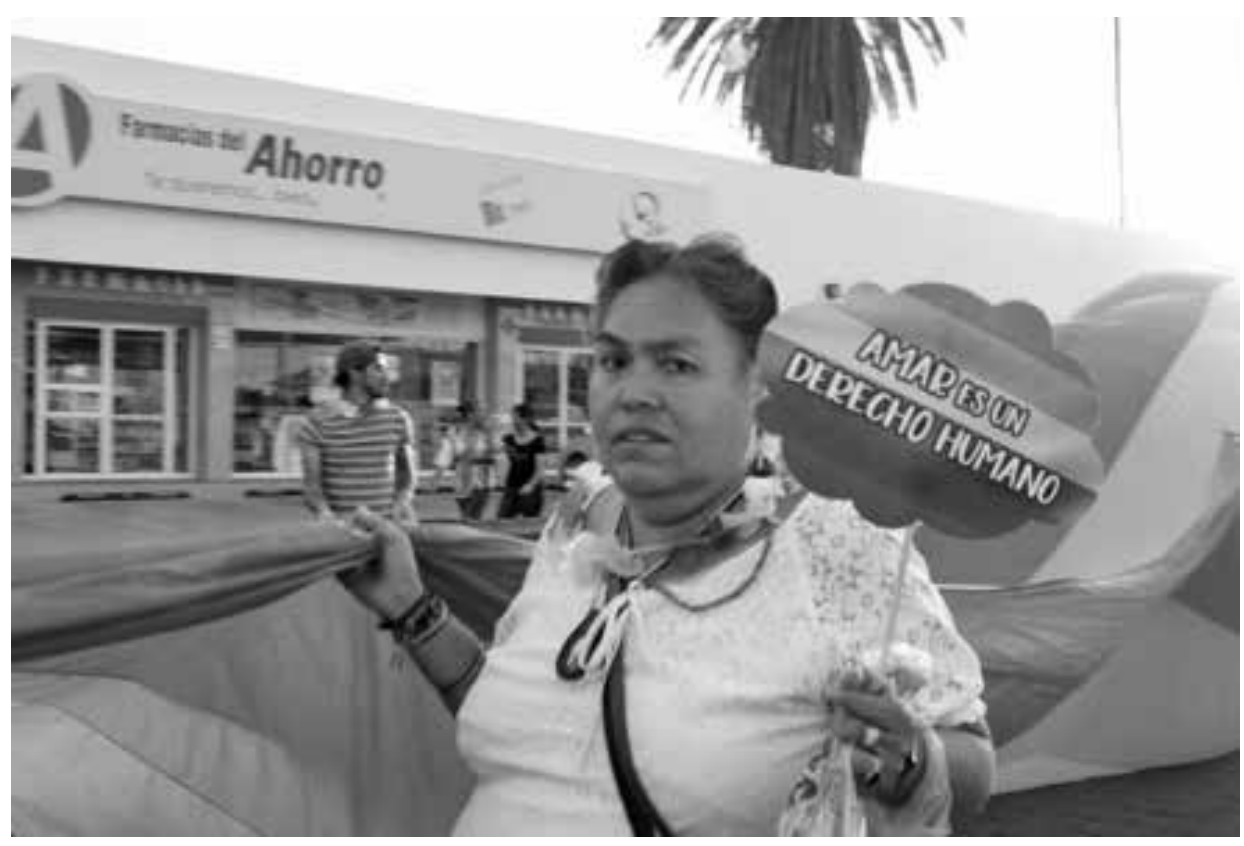

Foto: Tzintli Juárez. 
"Todos los DERECHOS PARA TODAS LAS PERSONAS" también fue una frase constante en las cartulinas. La potencia de este enunciado radica en mencionar los derechos, este concepto adquiere gran validez en escenarios democráticos y también en los no democráticos, pues el concepto derechos remite a la idea de una vida plena.

Cuando se dice "todos los derechos, todas las personas" va implícito el discurso de los derechos humanos, porque se apela a hacer extensivos los derechos a todos los seres humanos, y al tiempo lleva tácitamente la exigencia de reconocer como personas a las de la diversidad sexual y de género, ya que se establece un vínculo directo intrínseco entre derechos y personas. Es decir, no se puede pensar en las personas y que éstas no gocen de derechos, se crea una entidad que no se puede disociar.

No obstante, la palabra persona puede ser riesgosa, ya que con gran facilidad puede convertirse en un empaque que generaliza, homogeneiza y despolitiza a los sujetos, restándoles sus especificidades corpóreas e identidades específicas, lo que se ha hecho siempre con el modelo de ciudadanía normativa.

“DERECHOS IGUALES PARA LESBIANAS Y HOMOSEXUALES". Nuevamente se emplea la palabra derechos y la intención de este enunciado es hacer notar que los derechos son privilegios exclusivos de las personas heteronormadas, con lo que se deja fuera a quienes no lo son, y así, explícitamente, se apela a los derechos humanos, pues éstos sí tienen como finalidad la cobertura de una vida digna de todos los seres humanos sin diferencia alguna. No obstante, esta consigna desagrega la orientación sexual para reconocer a hombres y mujeres no heteronormados desde sus identidades y no subsumir la orientación sexual diversa a lo homosexual. No obstante, las personas trans y otras identidades quedan fuera o subsumidas a lo lésbico y lo homosexual.

“LA DIVERSIDAD NOS UNE". En un contexto internacional que se ordena a partir de la democracia y los derechos humanos, la diversidad se posiciona como un valor que ha desplazado a la idea de la pluralidad, porque supone reconocer todas las diferencias materiales corpóreas de los sujetos y no sólo la variedad de ideas.

La diversidad remite a la idea de la inclusión, el acercamiento de lo diverso que involucra convivencia e interacción desde el plano horizontal, y no tolerancia que remite a la idea de la verticalidad donde se posiciona el estatus de privilegio de ciertos grupos sobre otros.

Esta frase tiene como estrategia poner en tela de juicio las prácticas de exclusión que ejercen los grupos conservadores que se autodefinen como demócratas y defensores de los derechos humanos. Es decir, subraya la contradicción que hay en estos grupos entre sus ideas y sus prácticas.

"Donde hay amor hay familia". La idea de la familia es un constructo social muy potente y de alta legitimidad en el ámbito religioso, social y económico. Cabe recordar que la representación de la familia monogámica y patriarcal es producto del capitalismo. La mayor parte de las estrategias de mercado están ancladas en la idea de la familia, ésta es una entidad que vende, que disciplina, doblega y crea cuerpos dóciles.

La idea del amor se ha vinculado a la familia. Cuando se habla de familia, el sentimiento con que inmediatamente se relaciona es el del amor incondicional. Los sentimientos, en tanto instrumentos discursivos de lucha, son un recurso muy trascendente en las consignas y pancartas de las marchas del orgullo, porque se apela a la emoción validada positivamente, a los núcleos centrales de las representaciones de las personas que están guardados en el inconsciente y no a la razón.

Dentro de este sistema de creencias, fomentado por la Iglesia y el capitalismo a través de la mercadotecnia, las telenovelas y demás, nadie puede oponerse a la idea de: donde hay amor hay familia. El amor y la familia se colocan como un sentimiento y concepto inmaculados, que diluyen lo no heterenormado, trasladándolo de lo anormal a lo amoroso, para así complicar su ataque y discriminación.

El amor y la familia desde la perspectiva de la diversidad son deconstruidos en aras de trascender lo heteronormado, el orden cisgénero-binario (véase foto 3 ).

"AMOR es AMOR", "El AMOR Debe SER CElebrado NO CONDENADO", "El AMOR NO TIENE GÉNERo". COMO ya se estableció, el amor es un sentimiento virtuoso, es lo opuesto a la violencia, a la guerra, y siempre será noble y posibilita formas de vida mejores; por ello, el amor en sus diversas manifestaciones es y será siempre positivo, digno de celebrarse. En consecuencia, quien lo condena está a favor de la violencia.

Hay una deconstrucción del amor en su anclaje y apropiación heterosexual, para dar paso al amor entre las personas, y dejar de reducir este sentimiento a los genitales opuestos.

"El AMOR Es tan GRANDE gUe No CABE EN UN ARMARIo". Si el amor es positivo, generoso y virtuoso en sí mismo no puede quedar oculto. $\mathrm{El}$ amor es un sentimiento que dignifica a los sujetos y los humaniza, por tanto, debe ser visible. Esta frase cuestiona el disciplinamiento 


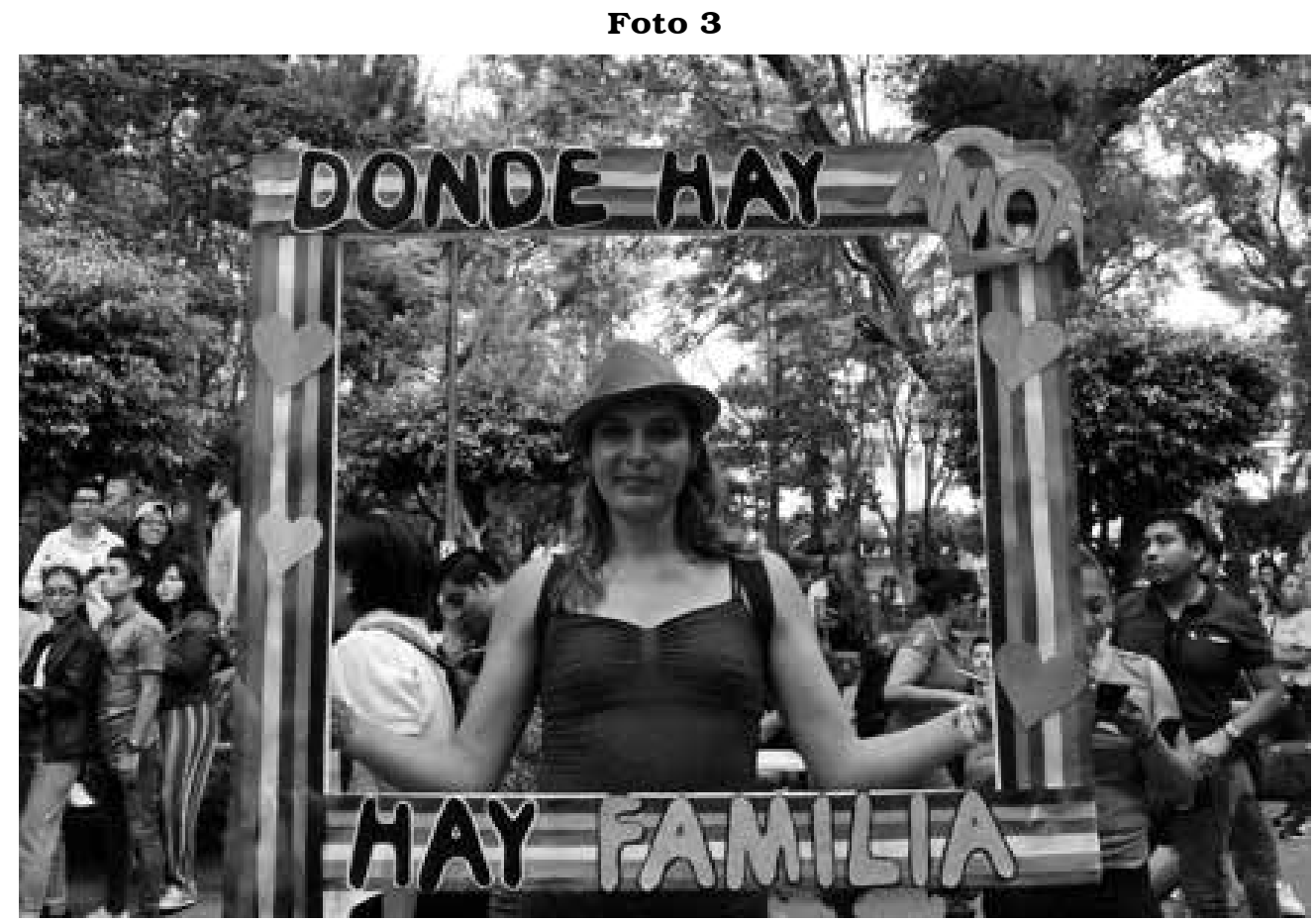

Foto: Tzintli Juárez.

que se ha hecho de las relaciones amorosas no heterosexuales, las cuales han sido confinadas a la vida privada y a la exigencia de no expresarse en la vida pública. Esta frase es una versión del siglo xxI de la frase: lo personal es político.

En síntesis, se puede decir que la estrategia discursiva de las personas LGBT en los últimos tiempos estriba en utilizar los mismos conceptos empleados por los grupos conservadores y asentarlos en la legitimidad de los derechos humanos para tratar de alcanzar lo inobjetable.

\section{Reflexiones finales}

La estructura de cemento social del viejo orden está teniendo severas cuarteaduras que ponen en peligro sus muros de carga. El modelo de ciudadanía normativa anclado en un prototipo que parecía sólido se desmorona poco a poco y se reconfigura desde el reconocimiento explícito del cuerpo, dando paso a entidades teóricas como la ciudadanía íntima y la ciudadanía sexual que aluden de forma general tanto al reconocimiento de todas aquellas áreas de la vida que parecen ser personales, pero que están reguladas a través de la esfera pública, como al reconocimiento de derechos de diversas formas de prácticas sexuales, de derechos relativos a la identidad propia y a las autodefiniciones.
Los movimientos de la diversidad sexual y de género apuntan a un nuevo orden de ciudadanía que sea capaz de dar cuenta de los cuerpos, la sexualidad, el género, las emociones, la identidad, las relaciones personales y los conflictos morales de la vida cotidiana.

Los derechos civiles, políticos y sociales que otorga la ciudadanía se están teniendo que abrir a resguardar cuerpos diversos acatando el orden supranacional imperante de los derechos humanos. Actualmente, nada se denuncia sin ampararse en esta máxima de verdad que se ha construido en el mundo capitalistademocrático. Diversos son los organismos y legislaciones internacionales que operan en pro de los derechos LGBT y, frente a la resistencia de los Estados por reconocer los derechos de las personas de la diversidad sexual y de género, se articula el litigio estratégico como una tercera vía legal que se ampara en los derechos humanos.

A 50 años de Stonewall, ciertas marchas del orgullo, como la de Nueva York, se privatizan, aparecen las marcas y las luchas de la diversidad sexual y de género se mercantilizan, pero en otros escenarios locales las manifestaciones que celebran el Día del Orgullo apenas empiezan a aparecer bajo estas estructuras de reacia mercantilización $\mathrm{y}$, aunque no sepan aún articularse del todo en una movilización política contundente, su visibilización en escenarios pequeños es en sí muy transgresor. 
Transcurrido medio siglo desde Stonewall, los conceptos retomados en las marchas poseen tintes políticos y emocionales. Así, se pasa de la idea de lo personal es político a lo emocional es político. Como nunca antes, el amor es la palabra clave y adquiere un significado particular en medio de contextos de inseguridad, violencia, desapariciones forzadas, feminicidos, transfeminicidios, crímenes de odio y demás asesinatos.

Las entidades conceptuales empleadas con mayor recurrencia en las marchas (familia y amor) no son nuevas, han existido y han sido legitimadas en extremo en el viejo orden $\mathrm{y}$, desde ahí, desde esos anclajes conceptuales convertidos en valores universales, se desafía hoy al orden anquilosado.

Pero también es cierto que las deconstrucciones más disruptivas y estridentes están posibilitando otras formas de desear, gozar, sentir y experimentar el erotismo entre los cuerpos, de forma distinta a lo impuesto por la biopolítica.

\section{Fuentes}

Argüello, Sofía

2014 ¿¿Tiene sexo el Estado? Imbricaciones entre las luchas políticas transgénero y el Estado en Ecuador, 2002-2013", en Alejandro Agudo Sanchíz y Marco Estrada Saavedra, Formas reales de la dominación del Estado, El Colegio de México, México, pp. 111-149.

BALISTRIERI, LEO

2019 "Los disturbios de Stonewall y el nacimiento del orgullo gay”, en Historia Hoy <https: / / www. historiahoy.com.ar/los-disturbios-stonewally-el-nacimiento-del-orgullo-gay-n 148> [22 de julio de 2019].

DIEZ, JoRDI

2011 "La trayectoria política del movimiento Lésbico-Gay en México”, en Estudios Sociológicos vol. XXIX, núm. 86, mayo-agosto, pp. 687-712.

EFEUSA

2019 "La rebelión de Stonewall, la noche que cambió la historia LGBTI", en EFEUSA, 21 de junio <https: / /www.efe.com / efe / usa / sociedad / la-rebelion-del-stonewall-noche-que-cambiohistoria-lgtbi /50000101-4006471>.

Enríguez, Gustavo

y Cecilia Martínez

2016 "Ciudadanía y cuerpos: reconfigurando la ciudadanía desde la diversidad", en Sinéctica. núm. 46, enero/junio, pp. 1-13.

Fuentes, Adriana

2015 Decidir sobre el propio cuerpo. Una historia reciente del movimiento lésbico en México, Univer sidad Autónoma Metropolitana-Xochimilco/ La Cifra Editorial, México.

García, Dora

2017 "Violencia y humillación sobre los cuerpos: La política como barbarie. Reflexiones éticopolíticas”, en Antonio Sustaita y Dora Elvira García, Estética de lo abyecto. Cuerpo y horizonte narrativo, Fontamara, México, pp. 15-46.
García Guitián, Elena

2010 "Problemas de la representación política", en Aurelio Arteta, Elena García, Román Máiz (eds.), Teoría política: poder, moral, democracia, Alianza Editorial, Madrid, pp. 387-401.

Le Breton, David

2002 Antropología del cuerpo y modernidad, trad. LÓPEZ, ERICKA de Paula Mahler, Nueva Visión, Buenos Aires.

2019 "Los derechos humanos para las personas LGBT y sus limitantes frente al modelo de la ciudadanía normativa", en Revista Rupturas, vol. 9, núm. 2, pp. 1-22 <https://doi. org/ $10.22458 /$ rr.v9i2.2520>.

Melucci, Alberto

1999 Acción colectiva, vida cotidiana y democracia, El Colegio de México, México.

Merleau-Ponty, Maurice

1993 Fenomenología de la percepción, trad. Jem Cabanes, Planeta-Agostini, Barcelona.

MuÑIZ, ELSA

2010 "Las prácticas corporales. De la instrumentalidad a la corporalidad", en Elsa Muñiz (coord.), Disciplinas y prácticas corporales. Una mirada a las sociedades contemporáneas, Anthropos/Universidad Autónoma Metropolitana-Azcapotzalco, México, pp. 17-50.

\section{Museo Memoria y Tolerancia}

2018 Exposición temporal Amor es amor. LGBT+ Identidad, amor y sexualidad, Museo Memoria y Tolerancia, México.

Observatorio de Reformas Políticas

EN AMÉRICA LATINA

2019 "Derechos LGBT en América Latina" < https: / / reformaspoliticas.org/wp-content/uploads / 2019/06/Diversidades-v_17_jun_19.pdf > [10 de julio de 2019].

RABOTNIKOF, NORA

2005 "Ciudadanía y derechos", en Manuel Canto (ed.), Derechos de ciudadanía. Responsabilidad del Estado, Icaria, Barcelona, pp. 29-48.

Sabsay, Leticia

2011 Fronteras sexuales. Espacio urbano, cuerpos y ciudadanía, Paidós, Buenos Aires.

Sánchez O., Alma Rosa

2009 "Cuerpo y sexualidad, un derecho: avatares para su construcción en la diversidad sexual", en Sociológica, año 24, núm. 69, enero-abril, pp. 101-122.

Serrato, AbraHam

Y ERICKA LÓPEZ

2018 "Del coming out a los derechos humanos en las demandas de las organizaciones de la sociedad civil del movimiento LGBT: estrategias discursivas de refugio", en Andamios, vol. 15 núm. 37, pp. 119-144, Dor: http: / /dx.doi.org/ 10.29092 / uacm.v15i37.633.

Trillo-FigueroA, Jesús

2016 "Lo personal es político: la educación para la ciudadanía", en Bioetica <https://www. bioeticaweb.com/lo-personal-es-politico-laeducacion-para-la-ciudadania/> $[22$ de julio de 2019].

YOUNG, IRIS 1998

"Imparcialidad y lo cívico-público. Algunas implicaciones de las críticas feministas a la teoría moral y política”, en Rafael del Águila, Fernando Vallespín y otros, La democracia y sus textos, Alianza Editorial, Madrid, pp. 445-470. 